\title{
Application of (2Z)-3-dimethylamino-2-(1H-indole-3-carbonyl) acrylonitrile in the synthesis of novel 3-heteroarylindoles: condensed meridianine analogs
}

\author{
Mohamed A. A. Radwan,, ${ }^{a}$ Eman A. Ragab, ${ }^{b}$ Mohamed R. Shaaban, ${ }^{b}$ and Ahmed O. H. \\ El-Nezhawy ${ }^{c}$
}

${ }^{a}$ Applied Organic Chemistry Department, National Research Centre, Dokki, Cairo, Egypt

${ }^{b}$ Chemistry Department, Faculty of Science, Cairo University, Giza, Egypt

${ }^{c}$ Chemistry of Natural and Microbial Products Department, National Research Centre, Dokki, Cairo, Egypt

E-mail:

\begin{abstract}
3-Dimethylamino-2-(1H-indole-3-carbonyl)acrylonitrile (2) was treated with phenylhydrazine, in refluxing basic ethanol, afforded a single product $N-1$ or $N-2$ substituted pyrazole. Basic promoted cyclization of enaminonitrile 2 with $\alpha$-heteroarylamines as $N, N$-1,3-dinucleophiles, condensed indolylpyrimidines as a new class of meridianine natural product analogs were obtained in moderate to good yields.
\end{abstract}

Keywords: Indole, alkaloids, enaminonitrile, meridianines, natural products, X-ray

\section{Introduction}

In recent years, there has been a rising interest in the synthesis of bioactive molecules from marine sources and their non-natural analogs. Various biologically active indole alkaloids have been produced from the marine invertebrates over the past few years. ${ }^{1-4}$ Along with these, 3substituted indoles represented promising structural class of marine alkaloids based upon their high degree of biological activity. The substitution at 3-position of the indole ring connecting an extra heterocyclic ring: imidazole (topsentins ${ }^{4,5}$ and nortopsentins ${ }^{6}$ ); dihydroimidazole $\left(\right.$ discodermindole $\left.^{7}\right)$; oxazole $\left(\right.$ martefrgin $^{8}$, amazol $\left.^{9}\right)$; oxadiazine (alboinon ${ }^{10}$ ); maliemide (didemidines ${ }^{11}$ ); piperazine (dragmacidon ${ }^{3}$ ); and pyrimidine (meridianins), recently isolated from the tunicate Splidium meridiaum. ${ }^{12,13}$ Furthermore, indole containing compounds has been reported to possess a wide variety of biological properties viz., anti-inflammatory, ${ }^{14-16}$ anticonvulsant, ${ }^{17}$ cardiovascular ${ }^{18}$ and antibacterial. ${ }^{19}$ 
Alkyl 3-(dimethylamino)propenoates and related enaminones have been also employed in the synthesis of functionalized heterocyclic compounds including natural products, and their analogs. $^{20-23}$

In continuation with an ongoing research program involving the synthesis of indole alkaloids, recently we reported utilization of (2Z)-3-dimethylamino-2-(1H-indole-3-carbonyl)acrylonitrile 2 as reagent for the preparation of meridianin $\mathrm{D}$ analogs, ${ }^{24}$ in addition to non-natural analogs, 3heteroarylindoles, ${ }^{27}$ from 3-cyanoacetyl indole. We now report utilization of enaminonitrile 2 and their transformations with $\mathrm{N}, \mathrm{N}$-dinucleophiles into $(1 \mathrm{H}$-indol-3-yl)pyrazole and condensed $(1 \mathrm{H}$ indol-3-yl) pyrimidines as a new structure of condensed meridianine analogs (Fig. 1).

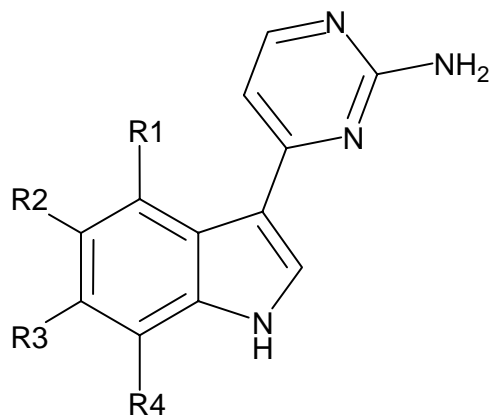

Meridianins: A R1=OH, R2=R3=R4=H

B R1=OH, R2=R4=H, R3=Br

C R1=R3=R4=H, R2=Br

D R1=R2=R4=H, R3=Br

E R1=OH, R2=R3=H, R4=Br

G R1=R2=R3=R4=H

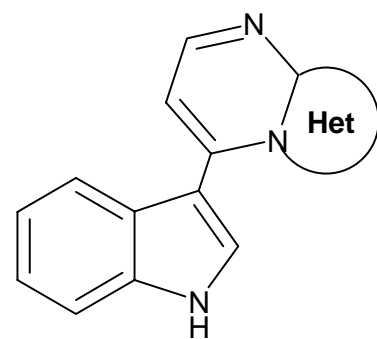

Condensed indolylpyrimidines

Figure 1. Structure of meridianines and condensed indolylpyrimidines.

\section{Results and Discussion}

Enaminones are important synthetic intermediates, particularly as building blocks for the preparation of many heterocyclic systems. ${ }^{28}$ And it can be used as starting materials for the preparation of $N-1$ or/and $N-2$ substituted pyrazoles. ${ }^{29-31}$ In fact, the reaction between enaminones and 1,2-bisnucleophiles may led to two possible regioisomers because the cyclization may proceed via two possible mechanisms that differ in their sequential nucleophilic attack/amine exchange reaction. Thus, when the enaminonitrile $2^{24,25}$, obtained by condensation of 3-cyanoacetyl indole $\mathbf{1}^{26}$ with dimethylformamide dimethylacetal (DMFDMA), was treated with phenylhydrazine, in refluxing ethanol, it afforded a single product $N-1$ or $N-2$ substituted pyrazoles (3a, 3b or 3c). The structure of the expected pyrazole 3c was excluded from the lack of cyano group in both IR and ${ }^{13} \mathrm{C}$ NMR spectrums. The regiochemistry of the reaction was determined by NOE experiment on the isolated product. As well, the pyrazole $3 \mathbf{b}$ was discarded on the basis of NOE experiment that showed no interaction between pyrazole proton $\mathrm{H}-5$ and the 
ortho protons of the phenyl group, allowing us to assign the structure of 5-amino-1-phenyl- $1 \mathrm{H}$ pyrazol-4-yl)(1H-indol-3-yl)methanone (3a) to this product. Moreover, there is a different in chemical shift of pyrazole proton signal in both other two possible compounds (3a or $\mathbf{3 b}$ ). Thus, the expected chemical shift of pyrazole proton ( $\mathrm{H}-5)$ of compound $\mathbf{3 b}$ is higher in frequency than pyrazole proton $(\delta=8.20, \mathrm{H}-3)$ of the obtained compound 3a, which was confirmed also by ${ }^{13} \mathrm{C}$ NMR and HSQC experiments at higher frequency $(\delta=140.40, \mathrm{C}-3)$, (Scheme 1). Moreover, the absolute structure of 3a was completely solved by X-ray diffraction analysis (Fig. 2).<smiles>CCC(=O)c1c[nH]c2ccccc12</smiles>

1

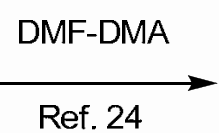

Ref. 24

3a<smiles>CN(C)/C=C(/C#N)C(=O)c1cc2ccccn2c1</smiles>

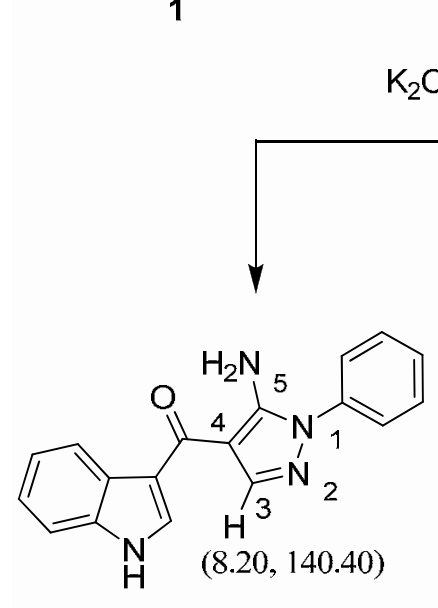

$\mathrm{K}_{2} \mathrm{CO}_{3}$, ethanol, reflux<smiles>CCO[NH+]([O-])c1ccccc1-n1nc(N)c(C(=O)c2c[nH]c3ccccc23)c1PC1CC2CCCCC21</smiles>

3b
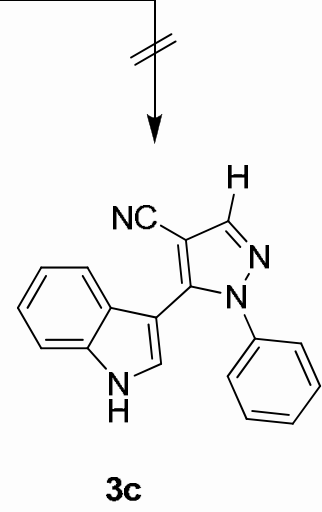

\section{Scheme 1}




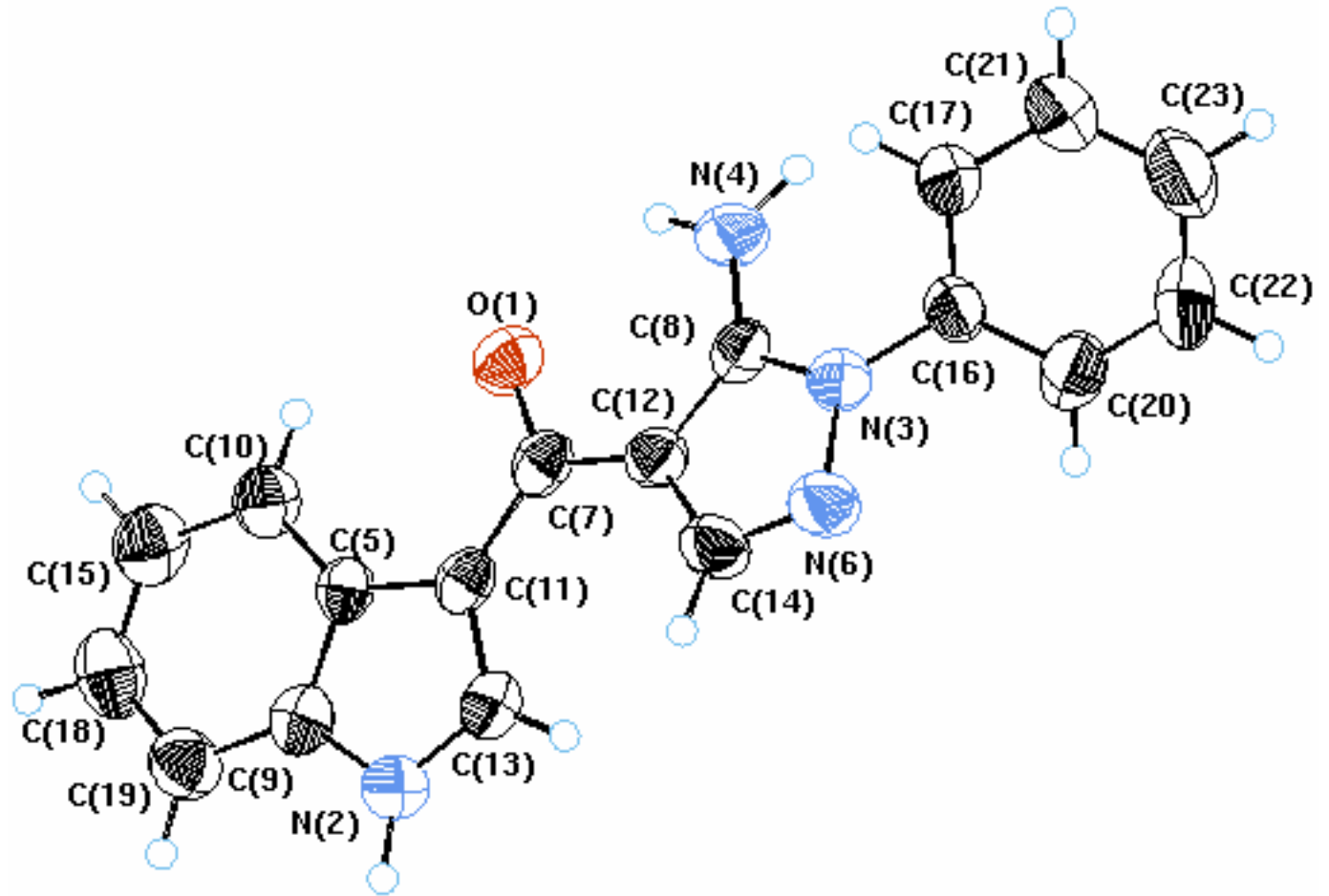

Figure 2. X-ray single crustal of compound 3a

Recently Stanovnik et al. reported the synthesis of both condensed indolylpyrimidones as meridianine analogs ${ }^{22}$ and polycyclic meridianin analogs with uracil structural unit. ${ }^{23}$

The behavior of enaminonitrile 2 toward some primary heteroarylamines with the amino group attached at the $\alpha$-position with respect to the ring nitrogen atom ( $N, N$-dinucleophiles) was also investigated. Thus, when compound 2 was treated with substituted 5-aminopyrazole derivatives 4a-d in the presence of a catalytic amount of piperidine, they afforded the corresponding $1 \mathrm{H}$-pyrazolo[1,5-a]pyrimidine derivatives $\mathbf{5 a - d}$, which considered as condensed meridianine analogs (Scheme 2). The structure of pyrazolopyrimidine derivatives 7a-d was excluded as a result of the lack of amino group in IR and also lack of carbonyl group in both IR and ${ }^{13} \mathrm{C}$ NMR spectrums. The other possible structure of $\mathbf{6 a - d}$ was ruled out on the basis of the ${ }^{1} \mathrm{H}$ NMR spectrum of the isolated products. For example, the ${ }^{1} \mathrm{H}$ NMR spectrum of compound 5a, taken as a typical example, which revealed a singlet signal at $\delta 8.77$ which was assigned for the pyrimidine $\mathrm{H}-2$ in structure $\mathbf{5}$ and not $\mathrm{H}-4$ in structure $\mathbf{6}$. Although spectral data seemed of no help in distinguishing between structures 5 and $\mathbf{6} .{ }^{32}$

However, structure $\mathbf{5 b}$, as an example, was definitely established for the reaction products by an alternate synthesis. For example, the reaction of 5-amino-3-methylpyrazole (4b) with DMFDMA and subsequent condensation of the formed amidine, 5- N-(N,Ndimethylaminomethylene)amino-3-methyl-1H-pyrazole ${ }^{36}$ (8), with 3-cyanoacetyl indole (1) 
afforded a product identical in all respects (TLC, mp, and spectra) with those of compound 7(1H-indol-3-yl)-2-methylpyrazolo[1,5-a]pyrimidine-6-carbonitrile (5b) (Scheme 2).

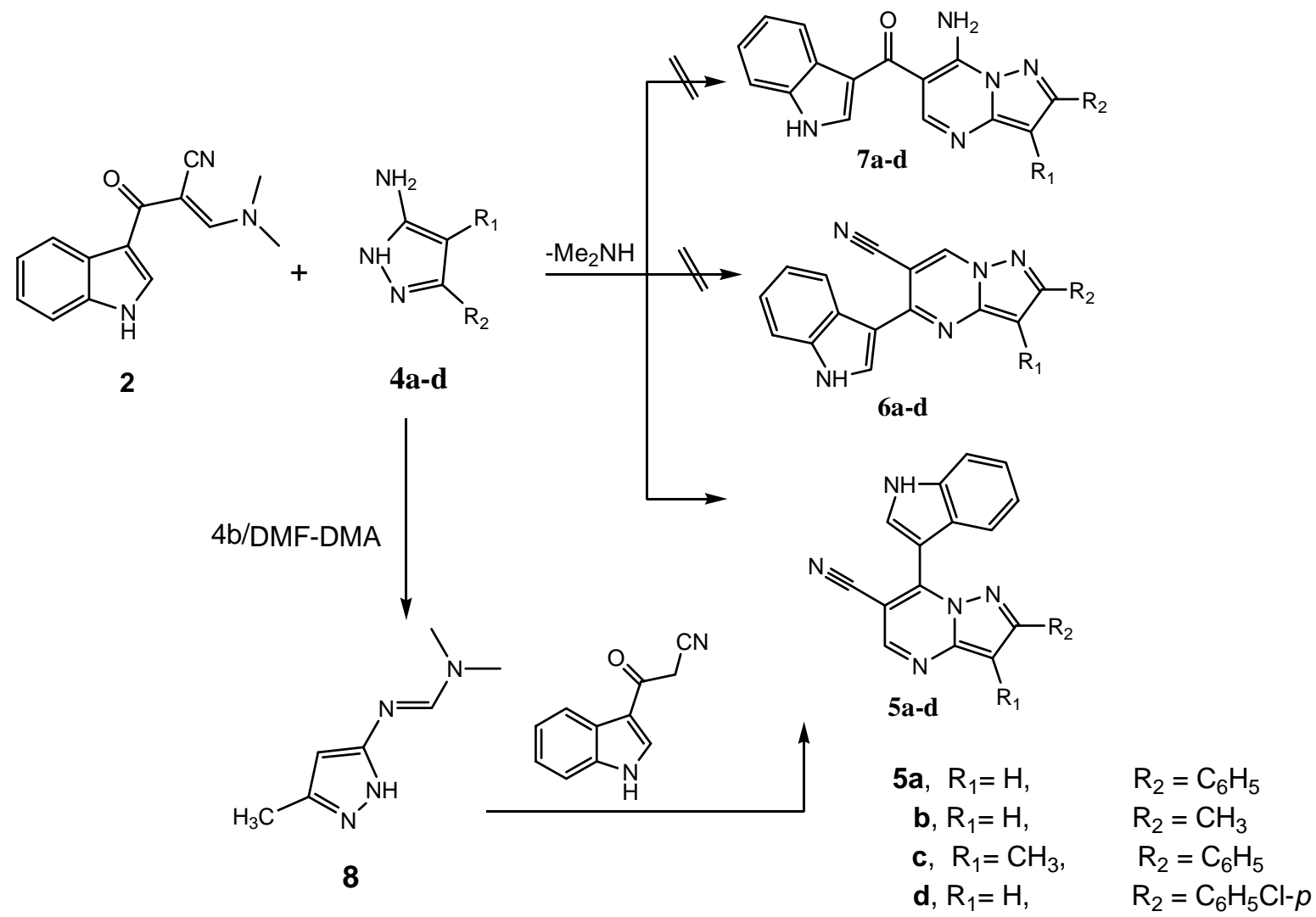

\section{Scheme 2}

Treatment of the enaminonitrile 2 with 2-aminobenzimidazole in pyridine under reflux gave only one isolable product. The isolated product was identified as 4-amino-3-(indolo-3carbonyl)pyrimido[1,2-a]benzimidazole (10) (Scheme 3). The IR spectrum of the reaction product revealed two bands due to amino and carbonyl functions. Moreover, the ${ }^{1} \mathrm{H}$ NMR spectrum of compound $\mathbf{1 0}$ revealed new singlet signal at $\delta 8.10$ due to pyrimidine proton and carbonyl signal in ${ }^{13} \mathrm{C}$ NMR spectrum at $\delta$ 182.35. The formation of product $\mathbf{1 0}$ is assumed to take place via the addition of the exocyclic amino group in 2-aminobenzimidazole to the activated double bond in the enaminonitrile 2 to give the acyclic non-isolable intermediate 9 which undergo intramolecular cyclization and subsequent aromatization via the loss of dimethylamine under the reaction conditions to afford the final product $\mathbf{1 0}$ as depicted in Scheme 3 .

The structure of the pyrimido[1,2-a]benzimidazole $\mathbf{1 0}$ was further confirmed by its alternate synthesis via the reaction of 3-cyanoacetyl indole (1) with $\mathrm{N}^{\prime}$ - $(1 \mathrm{H}$-benzimidazol-2-yl)- $N, N$ dimethylformamidine $(\mathbf{1 1})^{37}$ which afforded product identical in all respects (mp, mixed mp, 
TLC, IR, and mass spectra) with that obtained from the reaction of the enaminonitrile 2 with 2 aminobenzimidazole as shown in Scheme 3.
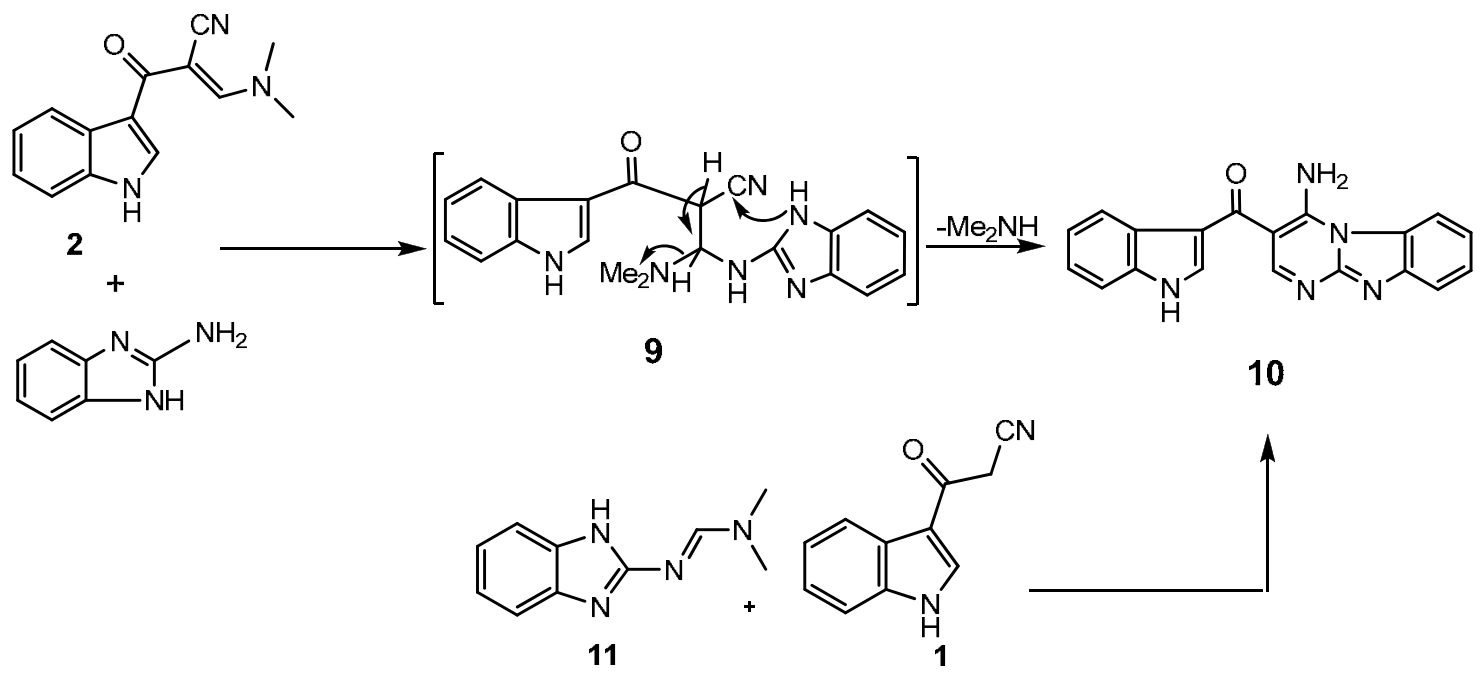

\section{Scheme 3}

The enaminonitrile 2 was also reacted with 2 -aminobenzothiazole in pyridine under reflux to give only one isolable product. The isolated product was identified as, the open form, 3(benzothiazol-2-ylamino)-2-(1H-indole-3-carbonyl)acrylonitrile (12) over the possible closed isomer 13 (Scheme 4). Thus, IR spectrum of the reaction product revealed two bands due to cyano and carbonyl functions. Moreover, the ${ }^{1} \mathrm{H}$ NMR spectrum of compound 12 revealed a characteristic singlet signal at $\delta 8.02$ attribute to the olefinic proton of the open structure. The structures of the reaction products were assigned based on their elemental analyses and spectral data.

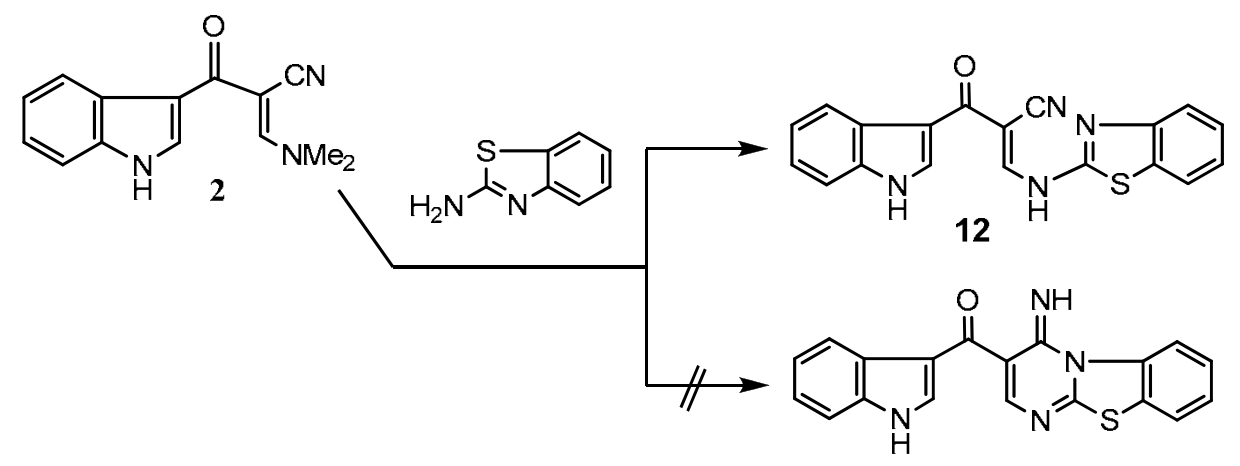

13

\section{Scheme 4}




\section{Conclusions}

In conclusion, we have clearly determined the structures of the reaction products of enaminonitrile 2 with $N, N$-dinucleophiles such as phenylhydrazine and primary heteroarylamines with the amino group attached at the $\alpha$-position with respect to the ring nitrogen atom under basic reaction conditions. Thus, from the reaction of enaminonitrile 2 with phenylhydrazine one regioisomer 3a can be obtained. Basic promoted cyclization of enaminonitrile 2 with $\alpha$ heteroarylamines as $N, N-1,3$-dinucleophiles, condensed indolylpyrimidines as a new class of meridianine natural product analogs were obtained. Thus, (2Z)-3-dimethylamino-2-(1H-indole-3carbonyl)acrylonitrile 2 is a suitable reagent for a one step preparation of indolyl substituted heterocycles.

\section{Experimental Section}

General Procedures. Melting points were determined on a Gallenkamp melting point apparatus. IR spectra were recorded on Shimadzu FT-IR 8101 PC infrared spectrophotometer. ${ }^{1} \mathrm{H}$ NMR spectra were recorded on a Jeol EX-270 MHz spectrometer using DMSO-d6 as solvent and TMS as the internal standard, ${ }^{13} \mathrm{C}$ NMR spectra were recorded on a varian Mercury VX 300 NMR using DMSO-d6 as solvent and TMS as an internal standard. Mass spectra were recorded on a Finnigan mat. SSQ-7000 GC-MS spectrometer. Microanalyses were performed at the Microanalytical Center of Cairo University. Aminopyrazoles 4a-d ${ }^{33-35} \mathbf{8}^{36} \mathbf{1 1}^{37}$ and 3 cyanoacetyl indole $(\mathbf{1})^{26}$ were prepared according to procedures in the literature.

(5-Amino-1-phenyl-1H-pyrazol-4-yl)(1H-indol-3-yl)methanone (3a). A mixture of enaminonitrile $2(2.0 \mathrm{~g}, 8.36 \mathrm{mmol})$, phenylhydrazine $(1.0 \mathrm{~mL})$ in ethanol $(20 \mathrm{~mL})$, in the presence of $0.5 \mathrm{~mL}$ piperidine, was heated under reflux for $6 \mathrm{~h}$. The solvent was removed by distillation under reduced pressure and the remainder was left to cool. The precipitated solid product was collected by filtration afforded 3a. Yield: $2.2 \mathrm{~g}$ (87\%) of a white solid; mp 271-273 ${ }^{\circ} \mathrm{C}$ (ethanol/DMF). IR (KBr): 3320-3390 $\left(\mathrm{NH}_{2}\right), 3165(\mathrm{NH}), 1696(\mathrm{C}=\mathrm{O}) \mathrm{cm}^{-1} .{ }^{1} \mathrm{H}$ NMR $(270$ MHz, DMSO-d6) $\delta 6.96$ (br s, 2H, NH ${ }_{2}$ ), 7.14-7.24 (m, 2H, H-5, H-6), 7.43-7.44 (dd, J=1.1, 7.8 Hz, 1H, H-7), 7.47-7.63 (m, 5H, Ph), 8.20 (s, 1H, H-3', Pyrazole), 8.27 (dd, J=1.1, 7.8 Hz, H, H4), 8.31 (s, $1 \mathrm{H}, \mathrm{H}-2), 11.87$ (br s, $1 \mathrm{H}, \mathrm{NH}) .{ }^{13} \mathrm{C}$ NMR (300 MHz, DMSO-d6): $\delta 104.3,111.8$, 115.9, 121.0, 121.5, 122.5, 123.4, 126.3, 127.3, 129.4, 131.0, 136.2, 137.8, 140.4, 150.4, 182.9. MS (ESI+): $m / z=303\left([M+H]^{+}\right)$. Anal. Calcd for $\mathrm{C}_{18} \mathrm{H}_{14} \mathrm{~N}_{4} \mathrm{O}: \mathrm{C}, 71.51 ; \mathrm{H}, 4.67 ; \mathrm{N}, 18.53 ; \mathrm{O}$, 5.29. Found; C, 71.54; H, 4.63; N, 18.51; O, 5.33 .

\section{Pyrazolo[1,5-a]pyrimidine derivatives (5a-d)}


Method A. To a mixture of the enaminonitrile $2(10 \mathrm{mmol})$ and appropriate aminopyrazole derivatives 4a-d (10 mmol) in absolute EtOH $(25 \mathrm{~mL})$ was added few drops of piperidine and the reaction mixture was refluxed for $6 \mathrm{~h}$, then left to cool. The formed solid product was filtered off and recrystallized from EtOH/DMF to afford the pyrazolo[1,5-a]pyrimidine derivatives 5a-d in $75-87 \%$ yield. The physical and spectral data of compounds 5a-d are listed below.

Method B. A mixture of 3-cyanoacetyl indole (1) (10 mmol) and an equivalent molar ratio of 5$N$-( $N, N$-dimethylaminomethylene)amino-3-methyl-1H-pyrazole $(\mathbf{8})$ in acetic acid $(20 \mathrm{~mL})$, was heated under reflux for $6 \mathrm{~h}$. The solvent was removed by distillation under reduced pressure and the remainder was left to cool. The precipitated solid product was collected by filtration. Recrystallization from DMF afforded product identical in all respects ( $\mathrm{mp}$, mixed mp, TLC, IR, and mass spectra with $\mathbf{5 b})$.

7-(1H-Indol-3-yl)-2-phenylpyrazolo[1,5-a]pyrimidine-6-carbonitrile (5a). Yield: 2.5 g (75\%) of a yellow solid; mp 265-267 ${ }^{\circ} \mathrm{C}$ (ethanol/DMF). IR (KBr): $3260(\mathrm{NH}), 2224(\mathrm{CN}) \mathrm{cm}^{-1} .{ }^{1} \mathrm{H}$ NMR (270 MHz, DMSO-d6) $\delta$ 7.20-7.33 (m, 2H, H-5, H-6), 7.46 (m, 3H, m, p-Phenyl), 7.47 (s, 1H, H-3', Pyrazole), 7.62-7.69 (m, 2H, o-Phenyl), 8.00 (dd, J=1.1, 7.8 Hz, 1H, H-7), 8.03 (dd, $J=1.1,7.8$ Hz, H, H-4), 8.54 (s, 1H, H-2), 8.77 (s, 1H, H-5 ', Pyrimidine), 12.40 (br s, 1H, NH). ${ }^{13} \mathrm{C}$ NMR (300 MHz, DMSO-d6): $\delta$ 91.9, 95.2, 102.6, 112.4, 116.9, 120.4, 122.2, 122.5, 124.9, 126.2, 128.7, 129.4, 131.6, 132.9, 136.2, 147.3, 149.7, 149.9, 156.9. MS (ESI+): $m / z=335\left(\mathrm{M}^{+}\right)$. Anal. Calcd for $\mathrm{C}_{21} \mathrm{H}_{13} \mathrm{~N}_{5}$ : C, 75.21; H, 3.91; N, 20.88. Found; C, 75.16; H, 3.89; N, 20.90 .

7-(1H-Indol-3-yl)-2-methylpyrazolo[1,5-a]pyrimidine-6-carbonitrile (5b). Yield: $2.3 \mathrm{~g}(84 \%)$ of a yellow solid; mp 199-201 ${ }^{\circ} \mathrm{C}$ (ethanol/DMF). IR (KBr): $3245(\mathrm{NH}), 2226(\mathrm{CN}) \mathrm{cm}^{-1} .{ }^{1} \mathrm{H}$ NMR (270 MHz, DMSO-d6) $\delta 2.43$ (s, 3H. CH $), 6.75$ (s, 1H, H-3', Pyrazole), 7.11-7.30 (m, 2H, H-5, H-6), 7.52 (dd, J=1.1, 7.8 Hz, 1H, H-7), 7.61 (dd, J=1.1, 7.8 Hz, H, H-4), 8.41 (s, 1H, $\mathrm{H}-2$ ), 8.70 (s, 1H, H-5 ', Pyrimidine), 11.73 (br s, 1H, NH). ${ }^{13} \mathrm{C}$ NMR (300 MHz, DMSO-d6): $\delta$ 14.3 , 91.9, 97.8, 102.6, 111.7, 120.4, 121.6, 122.4, 124.7, 129.4, 132.9, 136.1, 146.9, 149.5, 149.9, 156.4. MS (ESI+): $m / z=273\left(\mathrm{M}^{+}\right)$. Anal. Calcd for $\mathrm{C}_{16} \mathrm{H}_{11} \mathrm{~N}_{5}: \mathrm{C}, 70.32 ; \mathrm{H}, 4.06 ; \mathrm{N}$, 25.63. Found; C, 79.29; H, 4.11; N, 25.61.

7-(1H-Indol-3-yl)-3-methyl-2-phenylpyrazolo[1,5-a]pyrimidine-6-carbonitrile (5c). Yield: $2.8 \mathrm{~g}(80 \%)$ of a yellow solid; mp 214-216 ${ }^{\circ} \mathrm{C}$ (ethanol/DMF). IR (KBr): $3266(\mathrm{NH}), 2221(\mathrm{CN})$ $\mathrm{cm}^{-1} .{ }^{1} \mathrm{H}$ NMR (270 MHz, DMSO-d6) $\delta 2.56$ (s, 3H. $\mathrm{CH}_{3}$ ), 7.18-7.30 (m, 2H, H-5, H-6), 7.36 (m, 3H, m, p-Phenyl), 7.50 (m, 2H, o-Phenyl), 7.63 (dd, J=1.1, $7.8 \mathrm{~Hz}, 1 \mathrm{H}, \mathrm{H}-7$ ), 7.70 (dd, J=1.1, $7.8 \mathrm{~Hz}, \mathrm{H}, \mathrm{H}-4), 8.44$ (s, 1H, H-2), 8.76 (s, 1H, H-5 ', Pyrimidine), 12.37 (br s, $1 \mathrm{H}, \mathrm{NH}) .{ }^{13} \mathrm{C}$ NMR (300 MHz, DMSO-d6): $\delta$ 14.2, 92.0, 102.5, 110.2, 112.4, 116.9, 120.4, 120.8, 121.9, $122.5,124.8,126.5,128.3,128.6,131.1,132.7,136.1,145.5,147.2,149.8,154.3 . \mathrm{MS}(\mathrm{ESI}+)$ : $m / z=349\left(\mathrm{M}^{+}\right)$. Anal. Calcd for $\mathrm{C}_{22} \mathrm{H}_{15} \mathrm{~N}_{5}: \mathrm{C}, 75.63 ; \mathrm{H}, 4.33 ; \mathrm{N}, 20.04$. Found; C, 75.66; H, $4.30 ; \mathrm{N}, 20.09$.

2-(4-Chlorlphenyl)-7-(1H-indol-3-yl)pyrazolo[1,5-a]pyrimidine-6-carbonitrile (5d). Yield: $3.2 \mathrm{~g}(87 \%)$ of a yellow solid; $\mathrm{mp}>295{ }^{\circ} \mathrm{C}$ (ethanol/DMF). IR (KBr): $3271(\mathrm{NH}), 2220(\mathrm{CN}) \mathrm{cm}^{-}$ 1. ${ }^{1} \mathrm{H}$ NMR (270 MHz, DMSO-d6) $\delta$ 7.19-7.34 (m, 2H, H-5, H-6), 7.45 (s, 1H, H-3`, Pyrazole), 7.54 (d, 2H, J = 7.8 Hz, Ph), 7.58 (dd, J=1.1, 7.8 Hz, 1H, H-7), 7.68 (dd, J=1.1, 7.8 Hz, H, H-4), 
8.02 (d, 2H, J = 7.8 Hz, Ph), 8.52 (s, 1H, H-2), 8.75 (s, 1H, H-5 ', Pyrimidine), 12.32 (br s, 1H, $\mathrm{NH}) .{ }^{13} \mathrm{C}$ NMR $(300 \mathrm{MHz}$, DMSO-d6): $\delta 95.4,102.5,112.4,116.8,120.4,120.7,122.1,122.5$, $124.9,127.9,128.8,130.5,133.0,134.1,136.2,147.3,149.8,150.1,155.6 . \mathrm{MS}(\mathrm{ESI}+): \mathrm{m} / \mathrm{z}=$ $369\left(\mathrm{M}^{+}\right)$. Anal. Calcd for $\mathrm{C}_{21} \mathrm{H}_{12} \mathrm{ClN}_{5}$ : C, 68.20; H, 3.27; Cl, $9.59 \mathrm{~N}, 18.94$. Found; C, 68.23; H, $3.23 ; \mathrm{Cl}, 9.58 \mathrm{~N}, 18.97$.

\section{Synthesis of 4-amino-3-(indolo-3-carbonyl)pyrimido[1,2-a]benzimidazole (10)}

Method A. To a mixture of the enaminonitrile $2(10 \mathrm{mmol})$ and 2-aminobenzimidazole $(1.33 \mathrm{~g}$, $10 \mathrm{mmol})$ in pyridine $(25 \mathrm{~mL})$ was refluxed for $12 \mathrm{~h}$, then left to cool. The solvent was evaporated in vacuo and the residual solid was taken in $\mathrm{EtOH}$, then collected by filtration, washed with water, dried, and finally recrystallized from $\mathrm{DMF} / \mathrm{H}_{2} \mathrm{O}$ to afford the corresponding pyrimido[1,2-a]benzimidazole derivatives $\mathbf{1 0}$.

Method B. A mixture of 3-cyanoacetyl indole (1) (10 mmol) and $\mathrm{N}^{`}$-(1H-benzimidazol-2-yl)$N, N$-dimethylformamidine $(\mathbf{1 1})(1.88 \mathrm{~g}, 10 \mathrm{mmol})$ in ethanol $(20 \mathrm{~mL})$ and piperidine $(0.3 \mathrm{~mL})$ was heated under reflux for $10 \mathrm{~h}$, then left to cool. The precipitated solid product was collected by filtration, washed with ethanol, and finally recrystallized from $\mathrm{DMF} / \mathrm{H}_{2} \mathrm{O}$ to afford products identical in all respects ( $\mathrm{mp}$, mixed $\mathrm{mp}$, TLC, IR, and mass spectra) with compounds 10 prepared by Method A above. Yield: $2.5 \mathrm{~g}(76 \%)$ of a yellow solid; mp 179-181 ${ }^{\circ} \mathrm{C}$ (ethanol/DMF). IR (KBr): 3314-3410 $\left(\mathrm{NH}_{2}\right), 3177(\mathrm{NH}), 1692(\mathrm{C}=\mathrm{O}) \mathrm{cm}^{-1} .{ }^{1} \mathrm{H}$ NMR (270 MHz, DMSO-d6) $\delta 4.48$ (br s, 2H, NH 2 ), 7.01-7.10 (m, 2H, H-6', H-7`), 7.13-7.23 (m, 2H, H-5, H-6), 7.38 (dd, 1H, J =1.1, $7.8 \mathrm{~Hz}, \mathrm{H}-7$ ), 7.56 (dd, 1H, J =3.6, $7.5 \mathrm{~Hz}, \mathrm{H}-5$ ), 7.99 (s, 1H, H-2), 8.13 (dd, 1H, J = 3.6, 7.5 Hz, H-8'), 8.24 (dd, 1H, J =1.1, 7.8 Hz, H-4), 8.94 (s, 1H, H-2', Pyrimidine), 11.74 (br s, $1 \mathrm{H}, \mathrm{NH})$.

${ }^{13} \mathrm{C}$ NMR (300 MHz, DMSO-d6): $\delta 84.5,111.7,111.9,115.6,120.6,120.8,121.1,121.4,121.7$, $121.9,122.1,122.4,127.1,130.2,131.1,135.8,150.8,156.6,182.4$.

MS (ESI+): $m / z=327\left(\mathrm{M}^{+}\right)$. Anal. Calcd for $\mathrm{C}_{19} \mathrm{H}_{13} \mathrm{~N}_{5} \mathrm{O}: \mathrm{C}, 69.71 ; \mathrm{H}, 4.00 ; \mathrm{N}, 21.39 ; \mathrm{O}, 4.89$. Found; C, 69.71; H, 4.00; N, 21.39; O, 4.89.

Synthesis of 3-(benzothiazol-2-ylamino)-2-(1H-indole-3-carbonyl)acrylonitrile (12). Prepared from enaminonitrile $2(10 \mathrm{mmol})$ and 2-aminobenzothiazole $(1.50 \mathrm{~g}, 10 \mathrm{mmol})$ in pyridine $(25 \mathrm{~mL})$ was refluxed for $16 \mathrm{~h}$, recrystallized from $\mathrm{DMF} / \mathrm{H}_{2} \mathrm{O}$ to afford the corresponding pyrimido[1,2-a]benzimidazole derivatives 10. Yield: $2.7 \mathrm{~g}(78 \%)$ of a brown solid; mp 217-219 ${ }^{\circ} \mathrm{C}$ (ethanol/DMF). IR (KBr): $3277-3348(2 \mathrm{NH}), 2226(\mathrm{CN}), \mathrm{cm}^{-1} .{ }^{1} \mathrm{H}$ NMR (270 MHz, DMSO-d6) $\delta=7.10-7.16$ (m, 2H, H-6 ' H-7`), 7.17-7.22 (m, 2H, H-5, H-6), 7.44 (dd, $1 \mathrm{H}, \mathrm{J}=1.1,7.8 \mathrm{~Hz}, \mathrm{H}-7), 7.48$ (dd, 1H, J =3.6, $\left.7.5 \mathrm{~Hz}, \mathrm{H}-5{ }^{`}\right), 8.01$ (s, 1H, olefinic proton), 8.12 $\left(\mathrm{dd}, 1 \mathrm{H}, \mathrm{J}=3.6,7.5 \mathrm{~Hz}, \mathrm{H}-8^{`}\right), 8.26$ (dd, 1H, J =1.1, $\left.7.8 \mathrm{~Hz}, \mathrm{H}-4\right), 8.66$ (s, 1H, H-2), 11.60 (br s, $1 \mathrm{H}, \mathrm{NH}), 11.74$ (br s, 1H, NH). ${ }^{13} \mathrm{C}$ NMR (300 MHz, DMSO-d6): $\delta$ 84.5, 111.6, 111.8, 115.6, 120.6, 120.8, 121.1, 121.4, 121.7, 121.9, 122.1, 122.4, 127.0, 130.2, 131.1, 135.7, 150.8, 156.6, 182.3.MS (ESI+): $\mathrm{m} / \mathrm{z}=344\left(\mathrm{M}^{+}\right)$.Anal. Calcd for $\mathrm{C}_{19} \mathrm{H}_{12} \mathrm{~N}_{4} \mathrm{OS}: \mathrm{C}, 66.26 ; \mathrm{H}, 3.51 ; \mathrm{N}, 16.27$; O, 4.65; S, 9.31. Found; C, 66.29; H, 3.50; N, 16.24; O, 4.69; S, 9.33. 


\section{Acknowledgements}

The authors are grateful to the Central Services Unit at both National Research Center and Cairo University, Egypt, for running the spectral data.

\section{References}

1. (a) Faulkner, D. J. Nat. Prod. Rep. 1999, 16, 155. (b) Wipf, P. Chem. Rev., 1995, 95, 2115. (c) Alvarez, M.; Salas, M. Heterocycles 1991, 32, 1391. (d) Faulkner, D. J. Nat. Prod. Rep. 2001, 19, 1. (e) Hibino, S.; Choshi, T. Nat. Prod. Rep. 2002, 19, 148.

2. (a) Wright, A. E.; Pomponi,S. A.; Cross, S. S.; McCarthy, P. J. Org. Chem. 1992, 57, 4772.

(b) Capon, R.J.; Rooney, F. L.; Murray, M.; Collins, E. A.; Sim, T. R.; Rostas, J. A. P.; Butler, M. S.; Carroll, A. R. J. Nat. Prod. 1998, 61, 660.

3. Kohmoto, S.; Kashman, Y.; McConnell, O. J.; Rinehart, K. L.; Wright, A. Jr.; Koehn, F. J. Org.Chem. 1988, 53, 3116.

4. Sakemi, S.; Sun, H. H. J. Org. Chem. 1991, 56, 4304.

5. (a) Kawasaki, Y.; Yamashita, M.; Otha, S. J. Chem. Soc., Chem. Commun. 1994, 2085. (b) Kawasaki, Y.; Yamashita, M.; Otha, S. Chem. Pharm. Bull. 1996, 44, 1831.

6. (a) Bartik, K.; Braekman, J. C.; Daloze, D.; Stoller, C.; Huysecom, J.; Vandevyver, G.; Ottinger, R. Can. J. Chem. 1987, 65, 2118. (b) Tsuji, S.; Rinehart, K. L.; Gunasekera, S. P.; Kashman, Y.; Cross, S. S.; Lui, M. S.; Pomponi, S. A.; Diaz, M. C. J. Org. Chem. 1988, 53, 5446. (c) Kawasaki, Y.; Katsuma, H.; Nakayama, Y.; Yamashita, M.; Otha, S. Heterocycles 1998, 48, 1887.

7. Sun, H. H.; Sakemi, J. J. Org. Chem. 1991, 56, 4307.

8. Vervoort, H. C.; Richards-Gross, S. E.; Fenical, W.; Lee, A. Y.; Clardy, J. J. Org. Chem. 1997, 62, 1486.

9. Takahashi, S.; Matsunaga, T.; Hasegawa, C.; Saito, H.; Fujita, D.; Kiuchi, F.; Tsuda, Y. Chem. Pharm. Bull. 1998, 46, 1527.

10. (a) N'Diaye, Y.; Guella, G.; Chiasera, G.; Mancini, Y.; Pietra, F. Tetrahedron Lett. 1994, 50, 4147. (b) Guella, G.; Mancini, Y.; N'Diaye, Y.; Pietra, F. Helv. Chim. Acta 1999, 77, 1994.

11. Bergmann, T.; Schories, D.; Steffan, B. Tetrahedron 1997, 53, 2055.

12. Franco, L. H.; Joffè, E. B. K.; Puricelly, L.; Tatian, M.; Seldes, A. M.; Palermo, J. A. J. Nat. Prod. 1998, 61, 1130.

13. Jiang B., Yang C.-G., Xiong W.-N., Wang J. Bioorg. Med. Chem. 2001, 9, 1149.

14. Misra, U.; Hitkari, A.; Saxena,A.K.; Gurtu, S.; Shanker, K. Eur. J. Med. Chem. 1996, 31, 629. 
15. Andreani, A.; Rambaldi, M.; Locatelli,A.; Pifferi, G. Eur. J. Med. Chem. 1994, 29, 903.

16. Ebeid Mohamad, Y.; Lashine Sayed, M.; El-Adl Sobhy, M.; Abou Kull Mansour, E. Zagazig J. Pharm. Sci. 1994, 3, 40.

17. El-Gendy Adel, A.; Abdou Naida, A.; Sarhan El-Taher, Z.; El-Banna Hosny, A. Alexandria J. Pharm. Sci. 1993, 7, 99.

18. Kumar, A.; Saxena, K.K.; Gurtu, S.; Sinha, J.N.; Shanker,K. Indian Drugs 1986, $24,1$.

19. Dandia, A.; Sehgal, V.; Singh,P. Indian J. Chem. 1993, 32B, 1288.

20. Stanovnik, B.; Svete, J. Synlett 2000, 1077.

21. Svete, J. J. Heterocycl. Chem. 2002, 39, 437.

22. Jakše, R.; Svete, J.; Stanovnik, B.; Golobic, A. Tetrahedron 2004, 60, 4601.

23. Časar, Z.; Bevk, D; Svete, J.; Stanovnik, B.Tetrahedron 2005, 61, 7508.

24. Radwan, M. A. A.; El- Sherbiny M. Bioorg. Med. Chem. 2007, 15, 1206-1211.

25. Janosik,T.; Wahlström, N.; Bergman, J. J. Heterocycl.Chem, 2005, 42, 141.

26. Slatt, J.; Romero, I.; Bergman, J. Synthesis 2004, 2760.

27. Radwan, M. A. A.; Ragab, E. A.; Sabry, N. M.; El-Shenawy, S. M. Bioorg. Med. Chem. 2007, 15, 3832.

28. Greenhill, J. V. Chem. Soc. Rev. 1977, 6, 277.

29. Elassar, A.-Z.A.; El-Khair, A. A. Tetrahedron 2003, 59, 8463.

30. El-Taweel, F. M. A. A.; Elnagdi, M. H. J. Heterocycl. Chem. 2001, 38, 981.

31. (a) Speake, J. D.; Navas, F.; Bishop, M. J.; Garrison, D. T.; Bigham, E. C.; Hodson, S. J.; Saussy, D. L.; Liacos, J. A.; Irving, P. E.; Sherman, B. W. Bioorg. Med. Chem. Lett. 2003, 13, 1183-1186. (b) Al-Zaydi, K. M. Molecules 2003, 8, 541-555. (c) Pinto, D. J.; Orwat, M. J.; Wang, S.; Fevig, J. M.; Quan, M. L.; Amparo, E.; Cacciola, J.; Rossi, K. A.; Alexander, R. S.; Smallwood, M.; Luettgen, J. M.; Liang, L.; Aungst, B. J.; Wright, M. R.; Knabb, R. M.; Wong, P. C.; Wexler, R. R.; Lam, P. Y. J. Med. Chem. 2001, 44, 566.

32. Grenhill, J. V. Compr. Heterocycl. Chem. 1985, 5, 307.

33. Allen, G. R. J. Org. React. 1973, 20, 337.

34. Kuecklander, U.; Huehnermann, W. Arch. Pharm. 1979, 312, 515.

35. Takamizawa, A.; Hamashima, Y. Yakugaku Zasshi 1964, 84, 1113.

36. Al-Zaydi, K. M.; Al-Shiekh, M. A.; Hafez, E. A. J. Chem. Res. 2000, (S), 13 (M), 173.

37. Shaaban, M. R.; Saleh, T. S.; Mayhoub, A. S.; Mansour, A.; Farag A. M. Bioorg. Med. Chem. 2008, 16, 6344. 